\title{
Research Note Testing the Efficacy of Barrier Plantings for Limiting Sharpshooter Spread
}

\author{
Matthew P. Daugherty, ${ }_{1} *$ Barrett R. Gruber, ${ }^{1}$ Rodrigo P.P. Almeida, ${ }^{2}$ \\ Michael M. Anderson, ${ }^{3}$ Monica L. Cooper ${ }^{4}$ Yvonne D. Rasmussen, ${ }^{4}$ and Ed A. Weber ${ }^{4}$
}

\begin{abstract}
Barrier plantings have been used successfully in the management of plant diseases. Their effectiveness at limiting the incursion of the blue-green sharpshooter (Graphocephala atropunctata), an important vector of the pathogen Xylella fastidiosa, into vineyards was evaluated. Four barrier treatments (three tree species plots and one open control plot) were established and sharpshooters were monitored regularly over eight years. Barriers had intermittent effects, with significantly lower abundance of sharpshooters adjacent to tree plots in one year and significantly lower trapping frequency in three of the eight years. This inconsistency suggests that, on their own, barriers are likely to be an incomplete strategy for limiting pathogen spread into vineyards.
\end{abstract}

Key words: vector dispersal, vector source, Graphocephala atropunctata, Xylella fastidiosa, Pierce's disease, pathogen spillover

Landscape diversification can play an important role in pest management (Smith and McSorley 2000). Alternative host plants can limit pest abundance in a focal crop by supplementing natural enemy populations (Murphy et al. 1998) or by acting as trap crops (Zahavi et al. 2007) or pest repellents (Zaka et al. 2010). For vector-borne plant pathogens, a common cultural control measure is to plant alternative hosts along the periphery of fields to function as barriers to pathogen spread (Hooks and Fereres 2006). Such plantings can be effective barriers if they act as sinks for nonpersistently transmitted pathogens (Fereres 2000) or obstruct vector movement into the field (Dhanju et al. 1995). Here a study is reported of the utility of barrier plantings for curbing the movement of an important vector species, the blue-green sharpshooter Graphocephala atropunctata (Signoret) (Hemiptera: Cicadellidae), into vineyards.

\footnotetext{
'Department of Entomology, University of California, Riverside, CA 92521; ${ }^{2}$ Department of Environmental Science, Policy and Management, University of California, Berkeley, CA 94720; ${ }^{3}$ Department of Viticulture and Enology, University of California, Davis, CA 95616; and ${ }^{4}$ University of California Cooperative Extension, Napa, CA 94559.

*Corresponding author (email: matt.daugherty@ucr.edu)

Acknowledgments: This work was funded by the California Department of Food and Agriculture Pierce's Disease Research Program and USDA NRI grant \#2009-05174 to M.D.

This research was conceived and initiated by Ed Weber, who passed away before it was completed. The other coauthors dedicate this manuscript to his memory. The authors also thank Beringer Winery for their donation of land and labor in support of this work.

Manuscript submitted Jun 2011, revised Sept 2011, accepted Oct 2011. Publication costs of this article defrayed in part by page fees.

Copyright $(2012$ by the American Society for Enology and Viticulture. All rights reserved.
}

doi: 10.5344/ajev.2011.11068
Sharpshooter leafhoppers are among the most significant pests of grapevines in the western United States. Their pest status stems primarily from their ability to transmit the plant pathogen, Xylella fastidiosa (Purcell 1974, 1997). This xylemlimited bacterium is the causal agent of Pierce's disease in grapevines, which is characterized by progressive leaf scorch, defoliation, and eventual plant death (Purcell 1997). For northern coastal California vineyards, the dominant vector of X. fastidiosa is G. atropunctata. In this region there is a clear linkage between riparian habitats and nearby vineyards, with disease risk concentrated at the periphery of vineyards adjacent to riparian habitat (Purcell 1974, 1975). This effect occurs because certain riparian plant species are high-quality hosts for both X. fastidiosa and G. atropunctata (Purcell 1974, 1975, Purcell and Saunders 1999). Vector abundance and disease prevalence both decline dramatically at distances greater than $100 \mathrm{~m}$ from riparian habitat.

Given the potential for riparian habitats to be vector and pathogen sources for nearby vineyards, disease management has concentrated on the vineyard-riparian interface. Insecticide application at this interface reduces vector incursion into and disease spread within nearby vineyards (Purcell 1979). Moreover, removal of key riparian plant species that are competent $X$. fastidiosa reservoirs is recommended for constraining disease incidence (Pierce's Disease 2000). However, the feasibility of using barrier plantings between vineyards and riparian habitats to limit pathogen spread has not been investigated. Research in Southern California with another sharpshooter species, Homalodisca vitripennis (Germar), found that the vast majority ( $>97 \%$ ) of sharpshooters flew 5 $\mathrm{m}$ or less aboveground (Blua and Morgan 2003). Moreover, a $5 \mathrm{~m}$ tall artificial barrier screen interrupted substantially $H$. vitripennis movement (Blua et al. 2005). Thus, even moderate sized barrier plantings may limit G. atropunctata incursion into vineyards. 
The hypothesis that barrier plantings reduce G. atropunctata spillover into vineyards was tested via a long-term field experiment. Specifically, four barrier treatments (i.e., one of three tree species or an open control plot) were established at the vineyard-riparian interface, then sharpshooter populations were monitored regularly over eight years.

\section{Materials and Methods}

Study design. In winter 2001, 12 barrier plots were set up between an established vineyard in the Oak Knoll American Viticulture Area (Napa County, CA) and the Napa River $\left(38^{\circ} 20^{\prime} 31.82^{\prime \prime} \mathrm{N} ; 122^{\circ} 17^{\prime} 18.81^{\prime \prime} \mathrm{W}\right)$. Plots were located parallel to the vineyard and river, 5 to $8 \mathrm{~m}$ west of the riparian corridor and 13 to $15 \mathrm{~m}$ east of the vineyard edge (Figure 1). The next closest riparian corridor was farther than $1000 \mathrm{~m}$ to the west of the barrier plots. Each of the 12 plots was assigned to one of four treatments, with three replicates of each: redwood (Sequoia sempervirens (D. Don) Endl.), Monterey pine (Pinus radiata D. Don), Casuarina equisetifolia L., or open control. The three tree species were chosen because they are evergreen, grow relatively rapidly to substantial heights, and are thought to be poor reservoirs for $X$. fastidiosa. Each barrier plot was $\sim 60 \mathrm{~m}$ long and $6 \mathrm{~m}$ in depth. Tree plots consisted of three parallel rows of 30 trees at $\sim 2.0 \mathrm{~m}$ spacing, with drip irrigation. Collectively, the 12 plots ran the length of three vineyard blocks, a total of 16 ha, planted with Chardonnay on $\mathrm{SO} 4$ rootstock.

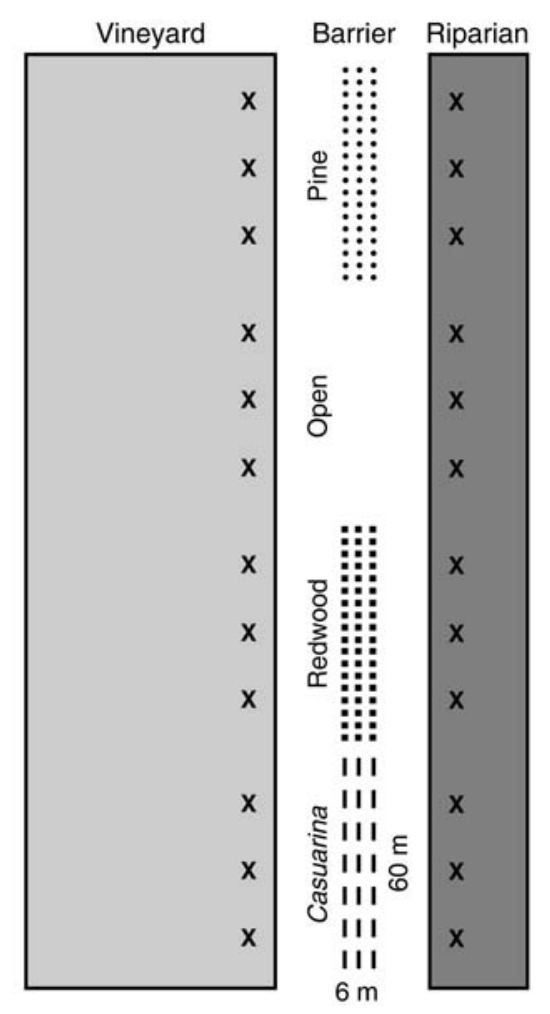

Figure 1 Schematic of the barrier treatment layout for one of the three experiment blocks. Each block consisted of four plots, one for each of three tree species and an open control, located between the riparian corridor and an adjacent vineyard. " $X$ " denotes the approximate placement of sticky traps on each side of the barrier. Figure not drawn to scale.
In spring 2001, three $23 \times 14 \mathrm{~cm}$ yellow sticky traps were set up to monitor vector populations on both vineyard and riparian sides of each barrier plot. Traps were placed so that one face was oriented toward the barrier. Vineyard traps were attached to the trellis a few vines from the edge of the vineyard at $\sim 1.5 \mathrm{~m}$ aboveground. On the riparian side, traps were attached to a post at the same height. All traps in each of the 12 plots were inspected every 7 to 10 days from the spring through fall in most years. At each census, the number of $G$. atropunctata was counted and then fresh traps were deployed. The total number of censuses over eight years was 194, ranging between 13 and 29 in a given year.

Data analysis. The effect of barrier treatments was evaluated at the growing-season timescale via two different metrics of $G$. atropunctata movement into vineyards. First, for a given plot, the proportion of all censuses over the year (e.g., 24 in 2001, 29 in 2002) for which at least one G. atropunctata was caught on the vineyard side of the plot was compared. These proportions were analyzed using a linear mixed effects model for which plot identity was defined as a random variable to serve as the treatment error (Pinheiro and Bates 2000). Barrier treatment and year were defined as fixed effects, and the number of $G$. atropunctata caught on the riparian side was a covariate. This structure accounts for the repeated measurement of plots over eight years. Model simplification methods were used to determine the most parsimonious adequate description of the data (Crawley 2009). A significant three-way interaction was followed up with a similar mixed effects model comparing the open treatment to the pine, redwood, and Casuarina treatments collectively. Pairwise comparisons among the three tree species were also made, with Bonferroni corrections for multiple tests. Next, the density of G. atropunctata on the vineyard side (\#/census) was compared over the season among treatments and years, using the same model structure and model simplification as before. A significant treatment-by-year interaction was followed by the same set of paired linear mixed effects models.

To understand whether barrier treatments affected sharpshooter incursion into vineyards at certain times of the year, G. atropunctata population dynamics within a season were analyzed. Given the high number of zeros that occurred in some years, this analysis was restricted to the two years with the most regular catches: 2003 and 2004. For each year, separately, the number of G. atropunctata caught on the vineyard side was compared, using linear mixed-effects models, for which treatment and census date were fixed effects, riparian G. atropunctata was a covariate, and plot identity was a random variable.

\section{Results and Discussion}

Effective implementation of a barrier program should be favored in the event of clearly definable vector source habitats. That is the case for G. atropunctata, which is well known to reside primarily in riparian habitats for much of the year, with short flights into vineyards occurring typically during a limited time during the season (Purcell 1974, 1979). Moreover, previous studies suggest that sharpshooters tend to fly 
near the ground (Blua and Morgan 2003) and artificial screens may limit their flights (Blua et al. 2005). Collectively, these factors should favor the efficacy of a barrier planted between vineyards and adjacent riparian habitat.

In the current study, the proportion of censuses for which there were any vectors caught on the vineyard side showed substantial variability among treatments and years. The main effect of barrier treatment was not significant, but there were significant interactions between treatment and year, treatment and riparian number, and a three-way interaction between treatment, year, and riparian number (Table 1). The open treatment had the highest catch frequency in 6 of the 8 years (Figure 2), significantly more than the trees, collectively, in three years: 2002,2003 , and 2006. This effect is largely attributable to the redwood treatment, which averaged approximately half that of the open plots in these years. However, the tree species did not differ significantly from each other in any of the years (Figure 2). Analysis of G. atropunctata cumulative density yielded similar results. The main effect of barrier treatment was not significant, but there was a significant interaction between barrier treatment and year in the final model (Table 1). Densities in 2003, and to a lesser extent 2004, were markedly higher than the other years (Figure 2). In 2003 the trees, collectively, resulted in significantly lower G. atropunctata density in the vineyard than the open treatment; the redwood treatment averaged less than half that of the open treatment. Densities did not differ significantly among the treatments in the other years (Figure 2). These results suggest that effects of barrier trees were inconsistent from year to year.

A time-by-treatment interaction might be expected in this type of study, because tree growth over the eight years could influence the permeability of the barrier plantings. Although the current study did not quantify barrier size and structure, anecdotally, it is clear that the trees grew (>five-fold) to upward of $15 \mathrm{~m}$ by the end of the study. Yet the nature of the treatment effects did not support the prediction that barrier effectiveness was accentuated over time. Rather, the treatment effects seem to be associated with overall vector abundance, which varied greatly among years. The strongest effects of the barriers were seen in three of the four years with the highest overall vector catches (i.e., 2002, 2003, 2006, but
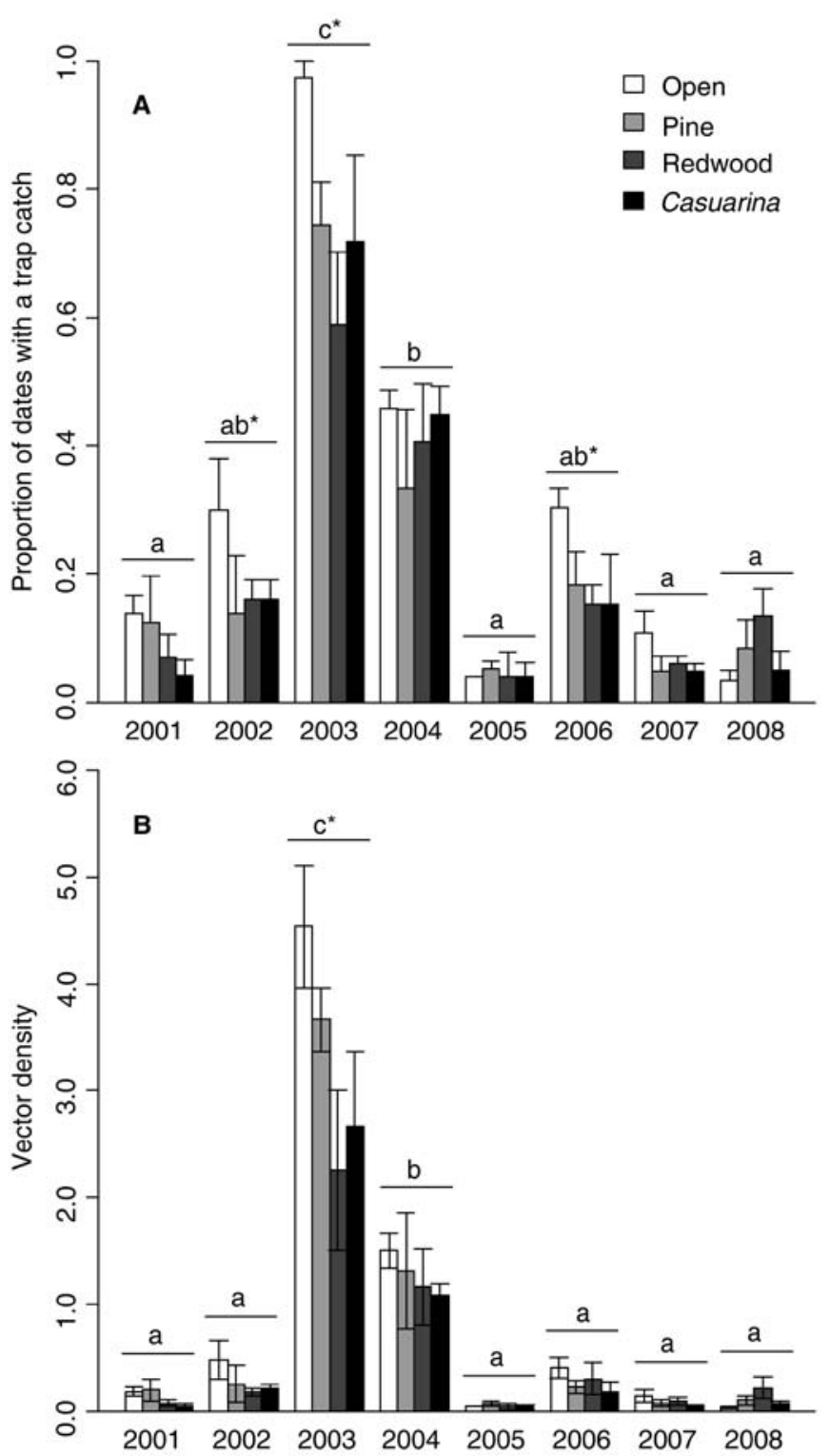

Figure 2 Mean $( \pm$ SE) $(A)$ proportion of dates over the year with at least one $G$. atropunctata caught in a given plot and (B) density on the vineyard side (\# / census) among treatments and years. Different letters above years denote significant overall differences in vector catches among years. * denotes significant differences between open plots and those with trees collectively. Pine, redwood, and Casuarina treatments did not differ significantly from each other in any years.

Table 1 Statistical results for the preferred models of the effects of barrier treatment $(T)$, year $(Y)$, riparian vector number $(R)$, and their interactions on the proportion of censuses with at least one $G$. atropunctata catch, cumulative density, and within-season dynamics in 2003 and 2004.

\begin{tabular}{|c|c|c|c|c|c|c|c|c|}
\hline \multirow[b]{2}{*}{ Source } & \multicolumn{2}{|c|}{$\begin{array}{c}\text { Proportion of censuses } \\
\text { with catch }\end{array}$} & \multicolumn{2}{|c|}{$\begin{array}{c}\text { Cumulative } \\
\text { density }\end{array}$} & \multicolumn{2}{|c|}{$\begin{array}{l}\text { Population dynamics } \\
2003\end{array}$} & \multicolumn{2}{|c|}{$\begin{array}{c}\text { Population dynamics } \\
2004\end{array}$} \\
\hline & $F_{d f \text { dfe }}$ & $\boldsymbol{P}$ & $F_{\mathrm{df}, \mathrm{dfe}}$ & $P$ & $F_{d f, d f e}$ & $P$ & $F_{\mathrm{df}, \mathrm{dfe}}$ & $P$ \\
\hline$\overline{\mathrm{T}}$ & $0.509_{3,8}$ & 0.6874 & $1.480_{3,8}$ & 0.6883 & $2.249_{3,8}$ & 0.1599 & $0.236_{3,8}$ & 0.9301 \\
\hline Y & $180.425_{7,24}$ & $<0.0001$ & $109.711_{7,45}$ & $<0.0001$ & $17.180_{12,95}$ & $<0.0001$ & $6.627_{25,199}$ & $<0.0001$ \\
\hline $\mathrm{R}$ & $8.154_{1,24}$ & 0.0087 & $5.046_{1,45}$ & 0.0296 & $0.284_{1,95}$ & 0.5954 & $1.495_{1,199}$ & 0.1496 \\
\hline $\mathrm{T}^{\star} \mathrm{Y}$ & $2.915_{21,24}$ & 0.0065 & $2.742_{21,45}$ & 0.0023 & $0.754_{36,95}$ & 0.8292 & $1.030_{75,199}$ & 0.4263 \\
\hline$T^{\star} R$ & $3.612_{3,23}$ & 0.0277 & $1.863_{3,45}$ & 0.1494 & - & - & - & - \\
\hline $\mathrm{Y}^{*} \mathrm{R}$ & $3.559_{7,24}$ & 0.0091 & $5.654_{7,45}$ & 0.0001 & - & - & - & - \\
\hline$T^{\star} Y^{\star} R$ & $2.030_{21,24}$ & 0.0482 & $-^{a}$ & - & - & - & - & - \\
\hline
\end{tabular}

aTerm not included in final model. 
not 2004). If barriers reduce vector incursion proportionately, then effect sizes are likely to be small in years of low vector abundance and documenting them would require additional effort compared to years of high vector abundance.

In addition to polyetic effects on sharpshooter incursion, it is plausible that barriers could affect the time of year that sharpshooters disperse into vineyards. Graphocephala atropunctata abundance throughout the growing season has been demonstrated to increase substantially with rising temperatures of the spring and summer (Feil et al. 2000). The seasonal timing of vector incursion is potentially important for Pierce's disease epidemiology, because the persistence of infections over the winter depends on when grapevines first become infected (Feil et al. 2003). Grapevines infected in spring have a far greater chance of staying infected than those later in the season. Within-season vineyard G. atropunctata dynamics in 2003 and 2004 were significantly affected by census date, but not barrier treatment or number of riparian G. atropunctata (Table 1). Both years showed peak sharpshooter abundance in late spring to early summer but without any clear seasonality in the relative differences among treatments (Figure 3). In 2003 G. atropunctata was consistently more abundant in open plots, whereas in 2004 all treatments were fairly comparable over time, suggesting that barriers are not likely to delay sharpshooter dispersal into vineyards. Given that the three trees evaluated were evergreen, great differences in barrier structure and sharpshooter movement over the season might not be expected.

Studies of aphid-borne viruses provide the best examples of how barrier plantings can be effective cultural control measures for limiting disease incidence. In a study of green peach aphid (Myzus persicae) and cotton aphid (Aphis gossypii) transmission of cucumber mosaic virus, pepper (Capsicum annuит) plots surrounded by sorghum (Sorghum vulgare) barrier plantings had $13 \%$ lower virus prevalence and nearly three-fold higher yield than open pepper plots despite no significant effect on vector movement (Fereres 2000). In these systems an important element of the barrier effect is that the pathogen is transmitted in a nonpersistent manner, meaning that the barrier plants can act as a pathogen sink (Hooks and Fereres 2006). Given that adult sharpshooters transmit $X$. fastidiosa in a persistent manner (Almeida and Purcell 2003), the pathogen sink effect of barrier plants is not likely to be epidemiologically significant in this system. Thus, although the current study did not quantify disease in the field, barriers effects on pathogen spillover into vineyards are likely to be weak in most years.

The results of the current study found inconsistent and limited effects of barrier plantings on sharpshooter incursion. However, there are at least two caveats worth considering before dismissing altogether barrier plantings as a sharpshooter control measure. First, the current study explored the effect of only three tree species, chosen primarily for their ability to achieve well over $5 \mathrm{~m}$ in height. Of these, redwood proved the most effective barrier, even though it did not reduce significantly sharpshooter incursion in most years. It is plausible that other plant species, even those of a shorter stature, may
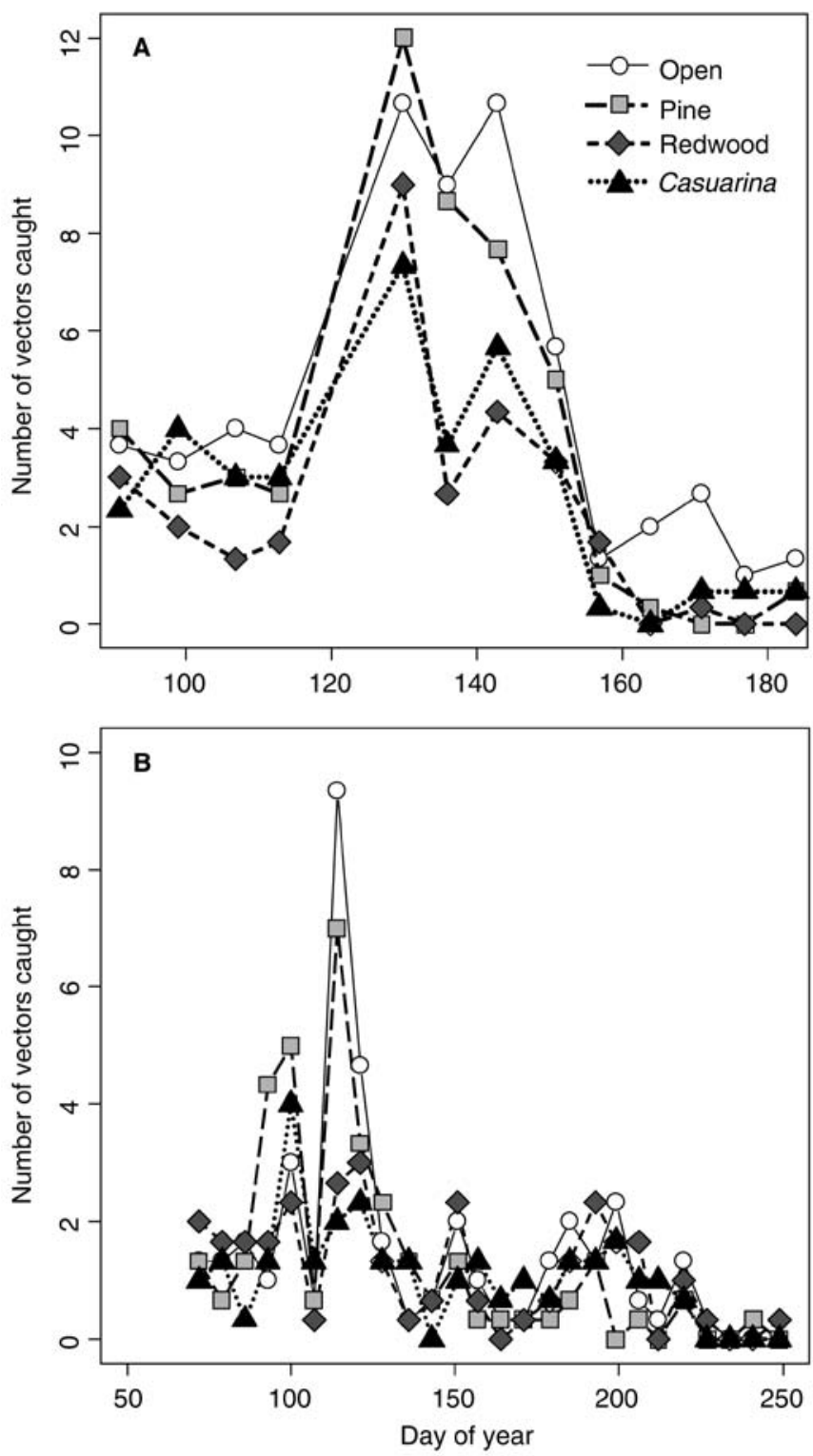

Figure 3 Mean number of $G$. atropunctata caught in vineyard plots among treatments over the (A) 13 censuses in 2003 and (B) 26 censuses in 2004. Error bars not shown to improve figure clarity. No significant within-season effects of barrier treatment occurred in either year.

form a barrier that is less permeable to sharpshooter movement. Second, the current study investigated the effect of individual treatments in isolation. Other studies suggest that barriers are most effective when used in tandem with other management strategies (Hooks and Fereres 2006). Specifically, insecticide application on barrier plants can improve their ability to serve as physical barriers to vector movement (Anandam and Doraiswamy 2002). Thus, incorporating barrier crops into existing chemical control programs may reduce sharpshooter movement into vineyards without necessitating application directly on the vines.

\section{Conclusions}

In this study the effectiveness of trees planted adjacent to a vector source habitat to limit sharpshooter leafhopper movement into nearby vineyards was tested. The results 
were mixed, with beneficial effects of barriers in a few years, but no effect of barriers on G. atropunctata in most years. Moreover, barriers did not delay sharpshooter movement into vineyards. Results suggest that barrier plantings alone are likely to be an unreliable strategy for limiting sharpshooter incursion and, therefore, Pierce's disease risk in vineyards.

\section{Literature Cited}

Almeida, R.P.P., and A.H. Purcell. 2003. Transmission of Xylella fastidiosa to grapevines by Homalodisca coagulata (Hemiptera: Cicadellidae). J. Econ. Entomol. 96:264-271.

Anandam, R.J., and S. Doraiswamy. 2002. Role of barrier crops in reducing the incidence of mosaic disease in chilli. J. Plant Dis. Prot. 109:109-112.

Blua, M.J., and D.J.W. Morgan. 2003. Dispersion of Homalodisca coagulata (Hemiptera: Cicadellidae), a vector of Xylella fastidiosa, into vineyards in Southern California. J. Econ. Entomol. 96:1369-1374.

Blua, M.J., K. Campbell, D.J.W. Morgan, and R.A. Redak. 2005. Impact of a screen barrier on dispersion behavior of Homalodisca coagulata (Hemiptera: Cicadellidae). J. Econ. Entomol. 98:1664-1668.

Crawley, M.J. 2009. The R Book. Wiley \& Sons, Chichester, UK.

Dhanju, K.S., S.C. Chowfla, and A.K. Handa. 1995. Effect of barrier crops and spacing on the incidence of mosaic disease and yield of French bean. Legume Res. 18:113-116.

Feil, H., W.S. Feil, and A.H. Purcell. 2000. Effects of temperature on the flight activity of Graphocephala atropunctata (Hemiptera: Cicadellidae). J. Econ. Entomol. 93:88-92.

Feil, H., W.S. Feil, and A.H. Purcell. 2003. Effects of date of inoculation on the within-plant movement of Xylella fastidiosa and persistence of Pierce's disease within field grapevines. Phytopathology 93:244-251.

Fereres, A. 2000. Barrier crops as a cultural control measure of nonpersistently transmitted aphid-borne viruses. Virus Res. 71:221-231.
Hooks, C.R.R., and A. Fereres. 2006. Protecting crops from nonpersistently aphid-transmitted viruses: A review on the use of barrier plants as a management tool. Virus Res. 120:1-16.

Murphy, B.C., J.A. Rosenheim, R.V. Dowell, and J. Granett. 1998. Habitat diversification tactic for improving biological control: Parasitism of the western grape leafhopper. Entomol. Exp. Appl. 87:225-235.

Pierce's Disease/Riparian Habitat Workgroup. 2000. Information Manual: Riparian Vegetation Management for Pierce's Disease in North Coast California Vineyards. [http://www.cnr.berkeley.edu/ xylella/control/PDNorthCoast/info.htm]

Pinhero, J.C., and D.M. Bates. Mixed-Effects Models in S and S-Plus. Springer Verlag, New York.

Purcell, A.H. 1974. Spatial patterns of Pierce's disease in the Napa Valley. Am. J. Enol. Vitic. 25:162-167.

Purcell, A.H. 1975. Role of the blue-green sharpshooter, Hordnia circellata, in the epidemiology of Pierce's disease of grapevines. Environ. Entomol. 4:745-752.

Purcell, A.H. 1979. Control of the blue-green sharpshooter and effects on the spread of Pierce's disease of grapevines. J. Econ. Entomol. 72:887-892.

Purcell, A.H. 1997. Xylella fastidiosa, a regional problem or global threat? J. Plant Pathol. 79:99-105.

Purcell, A.H., and S.R. Saunders. 1999. Fate of Pierce's disease strains of Xylella fastidiosa in common riparian plants. Plant Dis. 83:825-830.

Smith, H.A., and R. McSorley. 2000. Intercropping and pest management: A review of major concepts. Am. Entomol. 46:154-161.

Zahavi, T., S. Peles, A.R. Harari, V. Soroker, and R. Sharon. 2007. Push and pull strategy to reduce Hyalesthes obsoletus population in vineyards by Vitex agnus castus as a trap plant. Bull. Insectol. 60:297-298.

Zaka, S.M., X.N. Zeng, P. Holford, and G.A.C. Beattie. 2010. Repellent effect of guava leaf volatiles on settlement of adults of citrus psylla, Diaphorina citri Kuwayama, on citrus. Insect Sci. 17:39-45. 